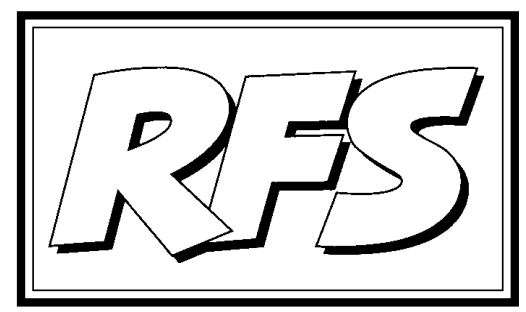

Revista de Fomento Social, 57 (2002), 579-594

\title{
Vivir en la sociedad de consumo
}

\section{Consejo de Redacción}

El consumo es un hecho mayor de nuestro mundo, al menos de nuestras sociedades desarrolladas. No en vano se emplea la expresión sociedades de consumo como una de sus caracterizaciones más significativas. Y no solamente porque consumir es necesario para mantener los ritmos de producción, sino además porque toda la vida humana y social está marcada por el consumo y por las funciones esenciales que éste desempeña. Evidentemente esta denominación no puede aplicarse a todos los pueblos de la tierra. Para muchos sería casi blasfema. Y aquí empiezan las paradojas: que los medios disponibles sean abundantes, hasta el punto de permitir a sociedades enteras dejarse llevar del afán consumista, mientras que no llegan a cubrir los mínimos precisos para una vida digna en grandes segmentos de población.

Pero no van a ser estas paradojas tan lacerantes el objeto directo de las páginas que siguen. En esta ocasión hemos decidido dedicar nuestras reflexiones al hecho del consumo en las sociedades de abundancia, casi de opulencia: en las sociedades de consumo. Para ello queríamos comenzar describiendo el alcance del consumo como fenómeno social y sus implicaciones humanas. Eso nos llevará a estudiar la defensa del consumidor, que hoy está conociendo un desarrollo jurídico y organizativo tan importante. Por fin, acabaremos con algunas propuestas y conclusiones. 


\section{Del consumo al consumismo}

No es el consumo propiamente dicho lo que será objeto de nuestra atención. Consumir, como alternativa al ahorro, es el empleo de los recursos económicos disponibles para satisfacer nuestras necesidades o nuestros deseos relacionados con el estándar de vida que queremos alcanzar. Es cierto que esta formulación de lo que es el consumo puede resultar excesivamente ambigua. Pero es suficiente para reconocer en el consumo una dimensión ineludible de la actividad económica, la cual es, a su vez, una componente importante de la vida humana.

Naturalmente el consumo así concebido representa para to do ser humano la posibilidad de poner objetos materiales al servicio de su propia idea de felicidad. Es más, el desarrollo económico ha permitido ampliar el abanico de posibilidades de consumo, y eso ha mejorado indiscutiblemente nuestro nivel de vida y, al menos en principio también, nuestra calidad de vida. Pero al mismo tiempo ha generado una dinámica que sí resulta preocupante. Nos encontramos así de lleno frente a lo que podemos llamar, para entendernos, el consumismo. Los regalos de los Reyes Magos y de Papá Noel, en las fiestas de Navidad, son un buen ejemplo de esta dinámica; la acumulación de juguetes y otros regalos terminan por saturar principalmente a los pequeños, que ya no saben que hacer con tantos cachivaches. Pero no es sólo este "pequeño consumo", muy importante por el volumen total que alcanza y por su significado como factor omni presente en nuestra sociedad; interesa también mencionar el "gran consumo", que muchas veces resulta un escándalo para el ciudadano, pero sirve otras muchas como justificación para el que tiene que conformarse con el que hemos llamado "pequeño consumo".

Porque esta dinámica consumista marca toda la existencia humana. Nos mete en una carrera desenfrenada de compras, que insiste tanto en la acumulación de objetos que reduce prácticamente a ello la calidad de vida, haciendo una peligrosa identificación de lo cuantitativo y lo cualitativo. El consumo se convierte, además, en signo de status social y criterio de comparación con los otros: lo que somos en la escala social queda determina do en primer término por nuestro nivel de consumo. Por otra parte, para mantener este nivel de gastos entramos indefectiblemente en una dinámica semejante por lo que se refiere al trabajo, puesto que éste es la vía más generalizada para acceder a la renta que permita dichos gastos.

Puede darse la paradoja de que para mantenerse en el nivel de consumo deseado haya que trabajar tanto que apenas quede tiempo para disfrutar de los 
bienes acumulados. Aunque quizás la paradoja se deshace si se tiene en cuenta que importa más poseer que disfrutar, porque es lo primero y no lo segundo lo que nos da el status deseado. ¿Puede llamarse a eso calidad de vida?

Pero hay más, el consumismo genera una determinada cultura marcada por el materialismo y la superficialidad. Ya lo hemos dicho: interesa acumular bienes más que disfrutarlos. Se cae así en un mundo de ostentación (piénsese en algunas celebraciones: fiestas, comidas de empresa, bodas y hasta primeras comuniones) que se justifican más desde el culto a las apariencias que desde la consideración de otros valores más profundos. Las películas de efectos especiales pueden servir de ilustración a todo esto: ¿no valora en ella el espectador más la forma que el contenido?

El consumismo tiene en el fenómeno de la moda un aliado inapreciable. $Y$ las modas, ya lo vemos, disminuyen el sentido crítico y la autonomía personal, al tiempo que favorecen el gregarismo y la pasividad: porque no es necesario pensar, sino sólo dejarse llevar, y-naturalmente- comprar. Las modas vuelven obsoletos los bienes de consumo de la noche a la mañana. Todos lo percibimos en los modos de vestir o en la música que se oye, o incluso en relación con bienes más costosos y, en principio, más duraderos (ordenadores, coches...).

\section{Consumo y sistema económico}

En el fondo el consumismo alimenta la convicción de que todo se resuelve en este mundo con dinero. Es la mercantilización de la vida toda. Una mercancía es, por definición, algo que se produce para ser intercambiado o que es susceptible de compraventa. La abundancia de mercancías disponibles y la lógica de la compraventa llegan a ser tan dominantes que sólo se perciben aquellas necesidades humanas que se adaptan a esta lógica. Ante otras necesidades ( psicológicas o espirituales) nos sentimos tan impotentes que nos desentendemos de ellas, a no ser en ciertas situaciones límite. Otras veces las forzamos buscando satisfacerlas con objetos de consumo: ¿no es eso lo que encontramos en ciertas formas de tratar el amor en los medios de comunicación o en el cine? Las necesidades que ocupan nuestra atención son aquellas que se someten dócilmente a la lógica mercantil. Por eso, lo repetimos, la vida humana y la sociedad toda se mercantiliza.

Esta dinámica consumista es, además, necesaria para que el sistema económico funcione. $\mathrm{Si}$, a pesar de los esfuerzos de algunos economistas más ponderados, se nos presenta continuamente como una evidencia indiscutible 
que el sistema funciona bien cuando los indicadores macroeconómicos de producción global crecen año tras año y trimestre tras trimestre, ¿quién puede hacer eso posible si no es una elevada tasa de consumo? Para producir más y crecer hay que consumir más, sin que importe mucho qué se produce y cuál es la relación entre el aumento de producción y la mejora en el auténtico bienestar humano. ¿No es ese el mensaje que nos transmiten día a día las intervenciones de muchos políticos y las declaraciones del mundo empresarial?

Pero no hay que ser linces para comprender los peligros de un mundo así. En términos globales, esta es la pregunta siempre inquietante y frecuentemente soslayada por inoportuna: ¿puede el planeta aguantar unos ritmos de consumo semejantes, aun cuando no lleguen a generalizarse a todos los países? ¿hasta cuándo podremos seguir creciendo así? Y eso, a pesar de que consumimos más de lo que necesitamos: frente a las imágenes espeluz nantes de niños de Etiopía literalmente en los huesos, leemos que uno de los grandes problemas de los niños norteamericanos es la obesidad... Por otra parte, el consumo, en la medida en que fomenta el pasivismo ocultándolo trasla sensación de que somos libres para comprar cuanto se nos antoja, se presta a todo tipo de manipulación.

La publicidad juega aquí un papel decisivo. Es cierto que el debate sobre las posibilidades de manipular que tiene la publicidad es un debate siempre inacabado. Pero sabemos del tema lo suficiente para comprender que, aunque el ciudadano no puede ser determinado desde fuera en todos sus hábitos de consumo, las posibilidades de ejercer alguna incidencia sobre él son abundantes. Si la publicidad implica siempre una relación entre productor y consumidor, esta relación es esencialmente asimétrica: el poder del productor es incomparablemente mayor porque su información, su especialización y sus recursos son muy superiores a los del ciudadano, que tiene que atender a ámbitos de consumo numerosos y diferenciados.

Al final de todo este recorrido puede uno preguntarse si la dinámica consumista contribuye a hacernos más felices como ciudadanos y como personas. No pensamos que la respuesta pueda ser alegremente afirmativa aunque veamos que el nivel de vida medio de nuestras sociedades crece ininterrumpidamente. El afán de consumo es esencialmente insaciable, no sólo por razones psicológicas, sino también como consecuencia de los estímulos externos para favorecer el consumo (¿hasta la creación de necesidades?). Por eso todo este dinamismo no conduce a ciudadanos satisfechos, sino permanentemente frustrados. En esta frustración interviene no pocas veces la competencia con los otros: el no tener lo que los demás o más que los 
demás es fuente de insatisfacción, cuando no de abierta frustración. Y el percibir, si es que se llega a percibir..., que la acumulación de objetos no nos hace más personas ni más auténticamente felices, puede derivar también en profundas crisis de frustración.

\section{Qué hacer como consumidores y como ciudadanos}

Quizás esta descripción de nuestra sociedad como sociedad de consumo ha forzado demasiado los aspectos negativos. Ya dijimos que el consumo representa, ante todo, una ampliación de oportunidades. Pero todo lo que en ello hay de positivo no puede hacernosignorar esta otra cara oscura del consumo, que todos intuimos, pero ante la que no siempre nos sentimos dispuestos a reaccionar.

Las posi bles reacciones irían en tres direcciones. Albert Hirschmann, hablando de la crisis de las organizaciones y las empresas, decía que ante ella cabían tres reacciones: salida, lealtad, voz. Podemos aplicar este esquema a nuestro caso. Ante el fenómeno del consumismo (que tiene mucho de crisis, en cuanto situación que está pidiendo un cambio) cabe:

a) Salirse, renunciando a ese mundo y automarginándose de él, huyendo a otro ambiente en el que se pueda vivir aceptablemente con un nivel mínimo de consumo, de sólo lo indispensable.

b) Insertarse en él desde la lealtad al sistema, lo que implica esforzarse por aumentar los mecanismos de protección del consumidor.

c) Actuar como voz para denunciar las contradicciones antes analizadas y proponer correcciones sustanciales.

La automarginación (salirse) es una postura digna de todo respeto, pero nos tememos que difícil de generalizar. Su eficacia de cara a un cambio de situación es exigua, pero muy importante en cambio su valor testimonial. Acercarnos a personas que viven una verdadera austeridad, no cicatera sino plenificante, es siempre una experiencia que obliga a autocuestionarnos.

La frontera entre las otras dos posturas (lealtad y voz) probablemente es difícil de fijar con exactitud. Cuando se analizan los sistemas de protección del consumidor en nuestras sociedades intuimos que tras ellos late un mezcla poco discernida de esas dos actitudes. Volveremos sobre esto una vez que hayamos examinado cómo se han desarrollado dichos sistemas en las últimas décadas. 


\section{El movimiento de defensa del consumidor: sus orígenes ${ }^{1}$}

Sus primeras expresiones se localizan en la década de los sesenta del siglo pasado. En ese momento histórico se agudizan los efectos de las grandes concentraciones económicas y de su instalación en las sociedades de consumo. Esa realidad contrastaba con lo que la teoría económica (cierta teoría económica...) nos quería hacer creer cuando nos presentaba a un consumidor que, a través de sus libres, medita das e informa das decisiones en el mercado, decidiría qué y cómo se produce: la denominada soberanía del consumidor. Teóricamente eso sería posible en un mercado de competencia perfecta, donde se da una verdadera libertad e igualdad en todos los agentes. Pero ¿habrá algo más ajeno a los mercados reales en que el consumidor se mueve cada día?

Por otro lado, los empresarios y sus asociaciones, ya sean de productores, importadores o distribuidores, a parecían normalmente organizados; mientras los consumidores y usuarios se encontraban, por lo general, aislados y en una clara situación de inferioridad económica, jurídica e informativa.

En una situación así la inferioridad y la indefensión de los consumidores y usuarios se da, no sólo respecto a sus intereses económicos, sino también en relación con su propia salud y seguridad. Recordemos algunos ejemplos que se hicieron tristemente famosos, precisamente en Estados Unidos, el país pionero y paradigma de las sociedades de consumo: el escándalo de la talidomida (que, todavía hoy, se sigue comercializando en el tercer mundo) y la retirada del Chevrolet Corvair por la General Motors.

El eco de estos escándalos en los medios de comunicación y la consiguiente preocupación y sensibilización de la opinión pública, provocaron las primeras reacciones del poder público traducidas, en un principio, en simples declaraciones de buenas intenciones. De hecho el arranque del movimiento de defensa de los consumidores y usuarios suele ubicarse en el mensaje que el presidente J. F. Kennedy dirigió al Congreso norteamericano el 15 de marzo de 1962 (en el que anualmente se celebra el día del consumidor) bajo el título "Protección de los intereses de los consumidores", donde se equiparaba al consumidor con el ciudadano-elector yse hacía alusión a los derechos de los consumidores y usuarios, destacándose los derechos de seguridad, información, elección y audiencia.

1 Para todo lo que sigue sobre protección del consumidor puede verse: M. PANIAGUA (2002), "La persistente protección jurídica de los consumidores y usuarios en un mundo en cambio (potenciación de los instrumentos jurídicos de defensa, en especial los demandados por el asociacionismo consumerista)", Estudios sobre Consumo, n. 60, pp. 9-56. 


\section{La defensa del consumidor en la Unión Europea}

Los primeros pasos del movimiento en defensa de los consumidores los dio en nuestro continente el Consejo de Europa, organización gubernamental especializada en la tutela de los derechos de los ciudadanos y de los derechos humanos. En la Resolución 543 de la Asamblea Consultiva del Consejo de Europa, denominada "Carta de protección del consumidor", publicada en mayo de 1973, se recoge una noción amplia de consumidor, prácticamente coincidente con la de ciudadano, y una enumeración de sus derechos.

Por su parte, en la Unión Europea la preocupación por la protección del consumidor tiene también una larga historia ${ }^{2}$. Decisivo es el paso que se da en el Tratado de la Unión (Maastricht 1991), donde se incorpora entre las acciones de la Unión para alcanzar sus fines un compromiso firme en este terreno ( art 129 A) : la Comunidad contribuirá a que se alcance un "alto nivel de protección de los consumidores" mediante las medidas dirigidas a la realización del mercado interior y mediante "acciones concretas que apoyen y complementen la política llevada a cabo por los Estados miembros a fin de proteger la salud, la seguridad y los intereses económicos de los consumidores, y de garantizarles una información adecuada".

El Tratado de Amsterdam en 1998 (Tratado Constitutivo de la Comunidad Europea) mantiene las previsiones anteriores y las completa con una enumeración de los derechos de los consumidores y usuarios (art. 153.1): “(Para) promover los intereses de los consumidores y garantizarles un alto nivel de protección, la Comunidad contribuirá a proteger la salud, la seguridad y los intereses económicos de los consumidores, así como a promover su derecho de información, a la educación y a organizarse para salvaguardar sus intereses".

Por su parte, la Carta de los Derechos Fundamentales de la Unión Europea (texto que arranca de la Cumbre de Colonia de junio de 1999) incluye entre los derechos económicos y sociales la protección de los consumidores en estos términos: “(Las) políticas de la Unión garantizarán un alto nivel de protección

2 Ya en octubre de 1972, en la cumbre de J efes de Estado y de Gobierno de la Comunidad Económica Europea, se manifiesta la preocupación por la protección del consumidor. Esta inquietud se concretará en abril de 1975 con la aprobación del denominado "Programa Preliminar de las Comunidades Europeas para una política de protección y de información de los consumidores", que ha tenido continuación hasta hoy: en mayo de 1981 se aprueba el "Segundo Programa"; en julio de 1985 se acuerda un "Nuevo Impulso" a la política de protección del consumidor. Este objetivo será reiterado luego en el Acta Única Europea. 
de la salud, de la seguridad y de los intereses de los consumidores".

La crisis alimentaria vivida por la Unión Europea ha focalizado las últimas iniciativas emprendidas. El Consejo Europeo de Niza (diciembre 2000) urge la necesidad de desarrollar rápida y completamente los principios introducidos por el Tratado de Amsterdam para la protección del consumidor. Por otra parte, se reconoce la conveniencia de "recurrir al principio de precaución cuando se determine la posibilidad de efectos nocivos para la salud o el medio ambiente y una evaluación científica preliminar, a tenor de los datos disponibles, no permita establecer con certeza el nivel de riesgo". Por fin se "toma nota" de la presentación de una Propuesta de la Comisión para crear una Autoridad Alimentaria Europea que entre en funcionamiento a comienzo de 2002.

\section{La defensa del consumidor en España}

En nuestro país algunas iniciativas tienen una historia relativamente dilatada. Ya en 1967 se promulgó el ambicioso Código Alimentario (carente de toda operatividad sin los reglamentos técnicos de desarrollo). En 1975 se creó el Instituto Nacional del Consumo, también de muy reducida eficacia. En esos años 70 comenzaron a surgir los primeros movimientos de consumidores, pero con escasa cobertura legal y bajas tasas de asociados.

La falta de normas jurídicas para articular la defensa de los derechos e intereses de los consumidores y usuarios obliga en ese tiempo a acudir a los conceptos generales presentes en los códigos decimonónicos que apelan a criterios éticos como la buena fe, la prohibición del abuso de derecho o los límites a la libertad de pactos representados por la moral o por el orden público.

Hay que esperar a la Constitución de 1978 para encontrar la base de un desarrollo jurídico posterior. En su artículo 51, incluido entre los principios rectores de la política social y económica se establece que "Ios poderes públicos garantizarán la defensa de los consumidores y usuarios, protegiendo, mediante procedimientos eficaces, la seguridad, la salud y los legítimos intereses económicos de los mismos". Están ahí recogidos los que podrían considerarse derechos de los consumidores. Y se añade que "los poderes públicos promoverán la información y la educación de los consumidores y usuarios, fomentarán sus organizaciones y oirán a éstas en las cuestiones que puedan afectar a aquéllos, en los términos que la ley establezca".

El desarrollo normativo posterior de este principio se da antes en dos comunidades autónomas: en 1981 se aprueba el Estatuto vasco del consumidor, 
y en 1983 la Ley catalana sobre determinadas estructuras comerciales y ventas especiales. Para el Estado habrá que esperar hasta 1984, en que se publica la Ley General para la defensa de los consumidores y usuarios (LCU). Los acontecimientos dramáticos que rodearon al denominado síndrome tóxico desde principios de mayo de 1981 impulsaron decididamente este desarrollo legislativo.

A pesar de su importancia, esta Ley tiene claras deficiencias técnicojurídicas: no sólo posee defectos de redacción y de sistemática u ordenación, sino que no llegó a concretar el mandato constitucional de proteger los derechos e intereses legítimos de consumidores y usuarios mediante "procedimientos eficaces". No obstante estas deficiencias, que son ciertas, hemos de destacar que la LCU manifiesta la voluntad del legislador de asumir y potenciar la protección del consumidor. La LCU pretende servir de eje 0 apoyo para futuras actuaciones y desarrollos normativos que, en buena medida, son demandadas por la Unión Europea. Ahora bien, muchas de las competencias normativas sobre protección del consumidor corresponden a las comunidades autónomas, cuyas leyes propias se aplican preferentemente, mientras la LCU queda como Derecho supletorio. Aunque Estatutos de Autonomía reclaman la competencia exclusiva en este terreno, en realidad se trata de una materia compartida entre Estado y comunidades autónomas.

De hecho, todas las comunidades autónomas siguieron el ejemplo de las dos que se adelantaron a la legislación estatal y han terminado asumiendo competencias sobre defensa del consumidor y usuario. Muchas de ellas han promulgado sus propias leyes sobre defensa de los consumidores y usuarios. Sin embargo hay que reconocer que en esta materia la legislación estatal y la legislación autonómica presentan importantes similitudes. No debe extrañarnos si retenemos que los supuestos de hecho regulados son sustancialmente idénticos, la orientación legislativa no es muy distinta y existen referencias normativas de obligado cumplimiento ( como las representadas por nuestra Constitución o por el Derecho comunitario).

Concretamente el Parlamento andaluz aprobó en 1985 la Ley de los consumidores y usuarios en Andalucía. En la Exposición de Motivos se declara su intención de proteger los derechos económicos y sociales de los consumidores y usuarios por dos mecanismos: el fomento del asociacionismo de consumidores y usuarios y la actuación de las administraciones públicas. Se enumeran como derechos de los consumidores y usuarios: la protección de la salud y seguridad, la reparación de los daños y perjuicios, la protección de los intereses 
económicos, el fomento del asociacionismo, la información de los consumidores y usuarios y la educación y formación de los consumidores y usuarios (art. 4). Se crea además el Consejo Andaluz de Consumo del que forman parte representantes de las organizaciones de consumidores, de las organizaciones empresariales y de las Administraciones radicadas en Andalucía.

\section{Dos concepciones en la defensa de los consumidores y usuarios}

Tras esta breve presentación de las iniciativas jurídicas para la protección del consumidor es conveniente reflexionar sobre los supuestos que las inspiran, que no siempre quedan explicitados en ellas. En efecto, es posible distinguir dos modelos, teóricamente diferenciables pero no inconciliables en la práctica.

Un primer modelo podríamos denominarlo complementario o conforme al mercado. Para él el objetivo político de defensa de los consumidores y usuarios es un punto más de estabilización del sistema de economía ( social) de mercado frente a las disfunciones propias del sistema o frente a los abusos en el ejercicio de sus derechos 0 en el cumplimiento de sus deberes de algunos agentes del sistema económico. La defensa del consumidor debe perseguir como objetivos, y utilizar como instrumentos: la política de la competencia, la política de la información y la mejora sustancial de la protección individual del consumidor. En realidad este modelo no cuestiona, de ahí su denominación, las estructuras de poder que se forman en los mercados, ni las correlaciones de fuerzas que estas estructuras mantienen.

Un segundo modelo es el llamado compensatorio: su objetivo no es adaptarse al mercado y aprovechar todas sus virtualidades, sino corregir de raíz su funcionamiento. Mediante la actuación de los poderes públicos y de las organizaciones de consumidores, propugnan y defienden la constitución de un contrapoder o poder fáctico en manos de las organizaciones de consumidores y usuarios dotado de la suficiente fuerza de presión y de negociación como para restablecer cierto equilibrio entre las fuerzas de los distintos agentes sociales que concurren al mercado. Este planteamiento va más allá de la simple protección del consumidor y usuario como contraparte contractual, o de la simple defensa de la competencia económica; asume, más bien, el objetivo de someter a control social a los poderes económicos, muchas veces carentes de otros contrapesos efectivos.

El modelo compensatorio incluye, de alguna manera, al modelo complementario: busca la coordinación entre la actividad dirigida a corregir los abusos en 
el ejercicio de la libre iniciativa económica y las actuaciones orientadas a propiciar y fomentar este poder compensador en manos de las organizaciones de consumidores. Pero lo específico suyo consiste en asumir que la defensa del consumidor no debe limitarse a garantizar un eficiente funcionamiento del sistema económico, sino que debe procurar también orientar a éste hacia la idea-fuerza de la calidad de vida, tan estrechamente vinculada con el horizonte (utópico, pero necesario) del desarrollo de la dignidad humana y de los derechos que le son inherentes, y con la participación de los ciudadanos y de los grupos en los que aquellos se integran en la vida política, económica, cultural y social.

Esto significa que, en nuestra opinión, el modelo complementario es insuficiente. Y, sin embargo, que es la orientación claramente dominante en la Unión Europea y en España ( y en los países del primer mundo). Más que la participación de los consumidores en la vida económica, se pretende informarlos y protegerlos individualmente, así como tutelar al sistema de economía de mercado en su conjunto. Se pretende que los consumidores y usuarios puedan ejercitar el reducido ámbito de soberanía que se les reconoce: el derecho a elegir en forma libre e informada sobre bienes y servicios seguros, y a obtener la reparación de los daños que se le infrinjan. Pero no se plantea directamente el derecho de los consumidores y usuarios, a través de sus organizaciones, a participar y decidir so bre el funcionamiento, la orientación y el reparto de poder en los mercados.

\section{Una información efectiva al consumidor como clave}

Posiblemente el lector habrá encontrado en esta distinción de modelos cierto eco de aquellas dos actitudes que designábamos antes con los términos de lealtad y voz. Para optar por ser voz y no limitarse a la lealtad es útil repasar todas las disfunciones y contradicciones que el consumo encierra cuando deriva en consumismo, y que hemos desarrollado más arriba.

Es cierto que queda mucho camino por recorrer para una adecuada protección jurídica del consumidor, que incluya cosas tales como: la potenciación de asociaciones de consumidores y usuarios, representativas, responsables, fuertes y autónomas; la puesta a punto de procedimientos judiciales y extrajudiciales baratos, rápidos y eficaces; el fomento de la información al consumidor.

Concretamente la información al consumidor se nos antoja esencial,. De hecho constituye el centro de la concepción dominante en la Unión Europea 
sobre la protección del consumidor, que responde al modelo que hemos llamado complementario. Es que, además, la política de información tiene unos frutos más inmediatos, es más impactante a la vista -especialmente en los medios de comunicación- y es más rentable electoralmente. Sin embargo, en la actualidad resulta no pocas veces insuficiente, máxime cuando la acumulación de capital está cómoda y firmemente asentada en el sector de la distribución de bienes y servicios, o cuando la creación artificial de nuevas necesidades es objetivo prioritario para el mantenimiento de tasas crecientes de producción y para la subsistencia del sistema, o cuando priman, en forma descarnada, los intereses económicos sobre los políticos, los sociales, los éticos, los culturales y los ideológicos. Todo esto explica que las denuncias de las asociaciones de consumidores sean con frecuencia inoperantes tanto por la escasa cuantía de las multas, cuando hay multas, como por la escasa atención de los organismos públicos.

En todo esto algunos ejemplos pueden ilustrarnos. Existen situaciones de flagrante violación de los derechos más elementales de los consumidores y usuarios (v.g.: el derecho a la salud y a la integridad personal) donde los consumidores están informados, las organizaciones de consumidores han realizado oportunas y reiteradas denuncias, se han abierto actuaciones judiciales y administrativas y, sin embargo, la lesión a los derechos persiste. Algunas de esas prácticas fueron considera das infracciones de importancia económica relativa, aunque más tarde derivaron en agudas crisis económicas para importantes empresas o para sectores enteros. Algunos ejemplos están en la mente de todos: Ios denominados productos milagro; las técnicas agresivas de ventas dirigidas a colectivos en situación de inferioridad como la infancia o la tercera edad; el engorde ilegal del ganado; la utilización sin control de medicamentos en animales destinados al consumo humano; la prescripción sin control de medicamentos con fines estéticos y el funcionamiento ilegal de clínicas médicas con estos fines; las importaciones ilegales de animales destinados al consumo humano, o de animales exóticos; las infracciones de etiquetaje en productos alimenticios, cuando no la venta de productos alimenticios sin etiquetar. Algunos de estos escándalos son tan recientes que no vale detenerse más en ellos. Pero sí cabe sacar de todo eso una lección: que los razonamientos y las decisiones rígidamente utilitaristas son, a la larga, las peores empresas económicas. La aplicación recta del principio de precaución disuadiría o echaría por tierra las que, deliberada e irónicamente, hemos denominado como infracciones de importancia económica relativa. 


\section{Una apuesta por la formación y educación de los consumidores y usuarios}

Pero, aun en la hipótesis de que tuviéramos bien asegurada la información al consumidor y todos los restantes mecanismos para la protección de éste, una pregunta surgiría que no dejaría de producir cierto desasosiego: protección del consumidor, sí, pero ¿al servicio de qué consumo? Si esta pregunta no se plantea, la protección del consumidor podría quedar reducida a un parche, 0 a una solución superficial porque no aborda los problemas de fondo.

Por eso, en nuestra opinión, la primera gran tarea en este campo es la formación y educación para el consumo. Y esta formación tiene que ser, ante todo, crítica, de modo que permita tomar distancia sobre el fenómeno del consumo globalmente considerado. En el fondo eso formaría parte de una verdadera educación para la libertad, entendida como autonomía. Al fin y al cabo, ése es el bien supremo del ser humano, que no se puede hipotecar al precio de una vida confortable gracias al consumo.

Es laudable que la educación para el consumo se vaya introduciendo, aunque lenta y tímidamente, en los ciclos de la enseñanza. En el marco de la Unión Europea, sólo la han desarrollado dos Estados: Grecia y Portugal. Pero hay que ir más allá, y extender la educación para el consumo a todas las etapas de la existencia. Es lo que se adivina en este pasaje del Plan Estratégico de Protección del Consumidor para el periodo de 1998-2001 de la Unión Europea: “(La) educación del consumidor constituye la piedra angular de la protección del consumidor. Esta debe entenderse como un proceso permanente que tiene por finalidad aportar al consumidor, de forma gradual, secuenciada y acorde a su nivel evolutivo, toda una serie de elementos cognitivos, procedimientos y técnicas de trabajo que le permitan desarrollar actitudes conscientes, críticas y solidarias, sintiéndose satisfecho de actuar de forma responsable ante los hechos de consumo. Debe responder a las necesidades actuales y a la formación de la sociedad futura".

Una educación para el consumo debe ir orientada a un consumo responsable, capaz de responder en cada momento a la doble pregunta: ¿qué compramos? ¿por qué compramos? Esta doble pregunta pretende conectar la necesidad personal con el medio para satisfacerla, y discernir si la necesidad es auténtica o inducida y si el objeto es el más adecuado.

Hablar de austeridad en este contexto no parece inútil, a pesar de no ser una virtud muy apreciada hoy día. Pero la austeridad, cuando no es egoísmo o 
tacañería, expresa inequívocamente el convencimiento de que el ser vale más que el tener. Rompe así la dinámica del consumismo, que atenaza a tantas personas.

Todas las grandes tradiciones religiosas han subrayado el peligro de ser engañados por el afán de poseer. El Programa de Naciones Unidas para el Desarrollo, en su informe de 1998, recogía este florilegio de máximas de distintas religiones:

Hinduismo: "Cuando se tiene el don dorado del contento, se tiene todo".

Islam: "Es difícil que un hombre cargado de riquezas ascienda el sendero abrupto que lleva a la felicidad".

Taoísmo: "El que sabe que tiene suficiente es rico".

Cristianismo: “¿Cuidado!Cuídate de todo tipo de codicia: la vida de un hombre no consiste en la abundancia de sus posesiones".

Confucionismo: "El exceso y la insuficiencia son igualmente defectuosos".

Budismo: "En su ansia de riqueza el hombre tonto se destruye como si fuera su propio enemigo".

Esta sabiduría ancestral, tan convergente, no debe ser fácilmente ignorada. Más aún en un mundo donde los recursos naturales empiezan a escasear, el medio ambiente a resentirse por la presión demográfica y consumista y la riqueza no se distribuye de forma que todo ser humano tenga garantizado un mínimo para vivir en dignidad. Este aspecto, que conscientemente hemos soslayado, como ya indicamos al comienzo, debe ser retomado al final de nuestras reflexiones, casi como una conclusión, porque introduciría una sana dosis de realismo en nuestro comportamiento como consumidores de países ricos.

\section{La intervención del Estado como complemento}

No hemos querido hacer de la intervención protectora del Estado el centro de nuestras propuestas. Hemos preferido, en cambio, poner el acento en la iniciativa de una sociedad formada por sujetos adultos y libres, que pueden ejercer su libertad gracias a una información adecuada y a una educación para el consumo. Pero todo ello no basta sin el apoyo de los poderes públicos.

Porque hay que reconocer, cuando se considera a productores y consumido- 
res frente a frente, que el poder de los primeros es muy superior al de los segundos. Por consiguiente, la relación entre ellos es claramente asimétrica y desigual. Una muestra significativa de esto que estamos diciendo la tenemos en el hecho de que hoy es la misma publicidad la que, con frecuencia, invita a consumidor potencial a elegir con libertad, mientras que está presionándolo para que opte en una determinada dirección. La información puede estar interesadamente tergiversada, y la educación puede no ser suficiente para contrarrestar esa presión. En pocas palabras, el ciudadano es siempre vulnerable ante quien maneja con más facilidad la información sobre los productos y los recursos de la comunicación.

Es preciso, por tanto, confiar en que también el mundo empresarial asuma la responsabilidad que le corresponde: y ya sabemos que la responsabilidad es tanto mayor cuanto mayor es el poder. La conciencia del indudable poder que tiene la empresa en nuestra sociedad ha llevado a hablar cada vez con más interés de la responsabilidad social de la empresa ${ }^{3}$. Y un aspecto de esta responsabilidad se refiere a la relación con el consumidor y con el ciudadano en general, los cuales se cuentan entre los principales stakeholders externos de la empresa.

Pero últimamente es el Estado -y aquí habría que invocar el principio de subsidiariedad- el que tiene que velar para que la cuerda no se rompa por donde es más débil, es decir, del lado del consumidor. Por eso la intervención pública es necesaria, no sólo mediante la protección jurídica, sino también favoreciendo las organizaciones de consumidores como fuerza social que contrarreste ese poder siempre mayor del sector productivo. No se trata de que el Estado defienda a un consumidor inerme y desinformado, porque eso sería paternalismo, sino de que complemente a un ciudadano adulto reforzando la capacidad de este para defender sus legítimos intereses y sus derechos.

\section{Conclusión}

Como en otras ocasiones con nuestros artículos editoriales, la Revista de Fomento Social pretende hacer reflexionar críticamente sobre el mundo en que vivimos, donde suele preocupar más el adaptarse a él y a provecharse de él que

3 Sobre la responsabilidad social de la empresa y el interés que despierta hoy ese tema puede verse, en este mismo número, el artículo de R. ARAQue, Una aportación al debate sobre el Libro Verde de la responsabilidad social de la empresa. 
el valorarlo y transformarlo. En esta ocasión hemos escogido algo que está omnipresente en nuestra vida de cada día: el consumo.

Hemos podido comprender que el consumo no es, en nuestras sociedades avanzadas, un conjunto de actos puntuales, sino un dinamismo vital. Por eso hemos pasado pronto del consumo al consumismo. Es cierto que, como consumidores, estamos muchas veces a merced del aparato productivo y de un sistema económico que se autovalora casi exclusivamente por su capacidad de producir. Desde esta perspectiva el consumidor, sin dejar de ser del todo el gran beneficiario del sistema, se convierte también en su principal víctima.

Por eso resulta tan importante analizar hoy el consumo con un espíritu crítico para recuperar su dimensión instrumental: el consumo debe estar al servicio de la persona y de su desarrollo. Este principio es tanto más relevante hoy cuanto mayor es el peligro de que esa jerarquía se invierta y se instrumentalice a las personas hasta inmolarlas en el altar de ese dios tan actual que es el crecimiento económico.

Plantearse el consumo desde la perspectiva del ciudadano lleva a hablar de protección del consumidor, de información al consumidor y de educación del consumidor. Son tres tareas que se complementan. Las tres contribuirán conjuntamente a hacer de nosotros, no ávidos consumidores, sino ciudadanos adultos que saben utilizar el consumo como un medio para ser auténticamente personas en un mundo en el que, a pesar de todos sus avances, éste sigue siendo el gran reto para todos y cada uno. 